\title{
Determination of Mercury in Biological Tissues by Graphite- furnace Atomic Absorption Spectrometry with an in-situ Concentration Technique
}

\author{
Li-li YANG, * De-qiang Zhang, *† and Qiu-xiang ZHOU** \\ * College of Chemistry \& Environmental Science, Hebei University, Baoding, 071002, P. R. China \\ **Department of Chemistry, Langfang Normal College, Langfang, 065000, P. R. China
}

\begin{abstract}
A method has been described for the determination of total mercury by graphite-furnace atomic absorption spectrometry (GFAAS) using an in-situ concentration technique with a Pd-Zr coating and a chemical modifier. The characteristic mass, which gives an integrated absorbance of $0.0044 \mathrm{~s}$, was found to be $42 \mathrm{pg}$ and an absolute detection limit ( $3 \sigma)$ of 33 pg was obtained with the proposed modifier. The total mercury values in standard reference materials, including Mussel (GBW08571), Bovine liver (GBW08306), Peach leaf (GBW08501) and Tea leaf (GBW080001), were determined using the proposed method, and the results were consistent with reference values. The method had been successfully applied to the determination of mercury in biological tissue samples with a recovery range of $94-105 \%$.
\end{abstract}

(Received December 3, 2001; Accepted May 9, 2002)

\section{Introduction}

Because of its high toxicity and pollution, mercury determinations at low levels and the evaluation of mercury pollution have received much attention in recent years. For the determination of mercury, cold vapor atomic absorption spectrometry (CVAAS) has generally been used for various samples due to its simplicity, high sensitivity and relative freedom from interferences, ${ }^{1-4}$ especially when the mercury vapor is trapped on a gold-platinum gauze for amalgamation before measurement by AAS. ${ }^{5-7}$ However, there are two disadvantages with this amalgamation technique, as reported by some authors. First, the collection efficiency of mercury may be impaired by moisture ${ }^{8}$ or other gaseous reaction products, which poison the surface of the amalgamation medium, ${ }^{9}$ necessitating occasional cleaning. ${ }^{4}$ Second, gas flow is often used to transport the vapor to the absorption cell during the heating of the collector to release the concentrated mercury. This means that the determination sensitivity is influenced by gas-flow rate, and that slight changes in the flow rate between measurements would also impair the reproducibility of the determination. ${ }^{10}$ In order to circumvent these problems, methods for the determination of mercury have been developed using a combination of the cold vapor generation technique, trapping in a porous gold-plated graphite mini-tube, ${ }^{11}$ a goldcoated $^{12,13}$ or a platinum-lined graphite tube, ${ }^{10}$ followed by atomic absorption spectrometric detection.

In addition, graphite-furnace atomic absorption spectrometry (GFAAS) was also applied using different chemical matrix modifiers for the determination of a low level of mercury with higher sensitivity and a lower detection limit with various matrix modifiers, ${ }^{14-16}$ especially when the mercury vapor had been concentrated in the graphite furnace with palladium and

$\doteqdot$ To whom correspondence should be addressed. palladium-rhodium as an absorbent and matrix modifiers. ${ }^{16,17}$ However, the instrumentation and chemical reagent of the GFAAS technique are often expensive.

The purpose of the present work is to propose a method for the determination of total mercury by GFAAS using an in-situ concentration technique. The proposed method has been applied to the determination of mercury in biological tissue samples with satisfactory sensitivity, detection limit, precision and recoveries.

\section{Experimental}

\section{Apparatus}

A Perkin-Elmer Model 1100B atomic absorption spectrophotometer equipped with an HGA-700 graphite furnace and a deuterium background corrector was used to measure mercury absorbance under the "gas stop" condition throughout. A high-intensity mercury hollow-cathode lamp (General Research Institute of Non-Ferrous Metals, Beijing, China) was operated as the light source with a lamp current of $1 \mathrm{~mA}$. The $253.7 \mathrm{~nm}$ resonance line of mercury was selected as the analysis line with a spectral slit of $0.7 \mathrm{~nm}$. Perkin-Elmer standard graphite tubes were used throughout and the sampleintroduction port was enlarged to a diameter of $2.5 \mathrm{~mm}$ with a drill bit for inserting a quartz tube connected to the outlet of a vapor generator. The generation of mercury vapor was achieved in a continuous mode in a glass cell using two channels of a peristaltic pump to deliver the sample and $\mathrm{KBH}_{4}$ solutions to the generator. The mixing and reaction of solutions were simultaneously finished in the cell. A piece of $5 \mathrm{~mm}$ i.d. silicone rubber tube was used for the connection between the outlet of the generator and the quartz delivering tube, the tip of which was inserted through the enlarged sample introduction port of the graphite tube and held in contact with the opposite interior wall during trapping of the mercury vapor in the Pd-Zr- 
Table 1 Furnace program for the determination of mercury by GFAAS with Pd-Zr chemical matrix modifier

\begin{tabular}{lcrcc}
\hline \multicolumn{1}{c}{ Step } & Temperature $/{ }^{\circ} \mathrm{C}$ & Ramp/s & Hold/s & Gasflow $/ \mathrm{mL} \mathrm{min}^{-1}$ \\
\hline Dry & 200 & 5 & 30 & 300 \\
Trapping & 700 & 2 & 30 & 300 \\
Pyrolysis & 900 & 10 & 20 & 300 \\
Atomization & 1800 & 1 & 5 & 0 \\
Clean & 2650 & 1 & 2 & 300 \\
\hline
\end{tabular}

coated graphite tube. The generated mercury vapor was carried by a stream of argon gas at a flow rate of $350 \mathrm{~mL} \mathrm{~min}^{-1}$. The heating program is summarized in Table 1. A ramp atomization was used instead of maximum power heating in order to avoid the loss of mercury.

A Qwave-3000 microwave oven (Questron Co. Ltd, USA) equipped with a computer was used to decompose the biological tissue samples and standard reference materials.

\section{Reagents}

A mercury standard stock solution, containing $1000 \mu \mathrm{g} \mathrm{mL}^{-1}$ of mercury, was prepared by dissolving $1.3534 \mathrm{~g}$ of mercury(II) chloride (Beijing Chemical Reagent Factory, Beijing, China) in $0.2 \%$ hydrochloric acid and diluting to $1000 \mathrm{~mL}$ with $0.2 \%$ hydrochloric acid. Working standard solutions were obtained by serial dilution of the standard stock solution with $0.2 \mathrm{~mol} \mathrm{l}^{-1}$ hydrochloric acid just before use.

A $2 \%(w / v)$ solution of potassium tetrahydroborate (Institute of Chemical regent, Tianjin, China) was prepared by dissolving an appropriate amount of $\mathrm{KBH}_{4}$ in deionized water without filtration and stabilization just before use.

The standard reference materials (Mussel (GBW08571), Bovine liver (GBW08501), Peach leaf (GBW08501) and Tea leaf (GBW080001)) were analyzed to demonstrate the accuracy of the proposed method.

A palladium modifier solution containing $1.25 \mathrm{mg} \mathrm{mL}^{-1}$ of palladium was obtained by dissolving $1.0414 \mathrm{~g}$ of palladium chloride in $10.00 \mathrm{~mL}$ of $0.1 \mathrm{~mol} \mathrm{~L}{ }^{-1} \mathrm{HNO}_{3}$ and diluting to $500.00 \mathrm{~mL}$ with water. A $20-\mu \mathrm{l}$ portion of a modifier solution containing of $25 \mu \mathrm{g}$ of Pd was injected into the furnace.

A zirconium modifier solution was prepared by dissolving an appropriate amount of $\mathrm{ZrOCl}_{2} \cdot \mathrm{H}_{2} \mathrm{O}$ in sub-boiling distilled water.

All reagents used were of analytical reagent grade, and subboiling distilled water was used throughout the experiments.

\section{Graphite tube}

A Pd-Zr coated graphite tube was obtained by injecting $20 \mu \mathrm{l}$ of a palladium solution into a $\mathrm{Zr}$-coated graphite tube before each atomization cycle. A Zr-coated graphite tube was prepared by injecting $250 \mu \mathrm{g} \mathrm{Zr}$ into a standard graphite tube according to Ref.18.

\section{Sample decomposition}

Approximately $1 \mathrm{~g}$ of samples were accurately weighed and transferred to microwave-oven decomposition vessels, to which $10 \mathrm{~mL}$ of concentrated nitric acid was added. The vessels were closed and the samples were decomposed in the microwave oven under control of a note-book computer. The samples were subjected to a maximum temperature of $195^{\circ} \mathrm{C}$ and a maximum pressure of $1.242 \mathrm{kPa}$. After the digestion was complete, excess nitric acid was removed from the sample solutions by lowtemperature heating. The solutions were transferred to $25-\mathrm{mL}$

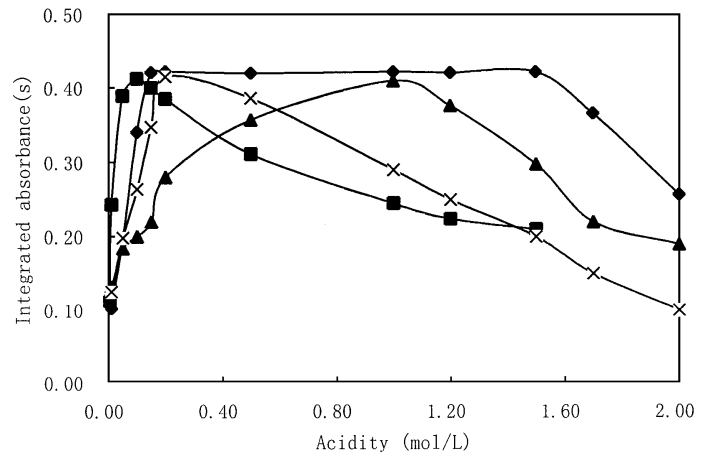

Fig. 1 Effect of the acidity condition on the integrated absorbance of $4 \mathrm{ng}$ of mercury: ( ) hydrochloric acid, ( $\mathbf{\square})$ perchloric acid, ( $\mathbf{\Delta})$ acetic acid and $(x)$ nitric acid.

volumetric flasks and diluted to the mark with $0.2 \mathrm{~mol} \mathrm{l}^{-1}$ hydrochloric acid.

\section{Procedure}

A $20 \mu \mathrm{l}$ of palladium modifier solution containing $25 \mu \mathrm{g}$ of $\mathrm{Pd}$ was injected into a $\mathrm{Zr}$-coated graphite tube with an Eppendorf microlitre pipette fitted with a disposable polypropylene tip, and dried at $150^{\circ} \mathrm{C}$. After a $2 \mathrm{~mL}$ portion of a sample solution containing about $4 \mathrm{ng}$ of mercury in $0.2 \mathrm{~mol} \mathrm{~L}^{-1} \mathrm{HCl}$ was transferred to a vapor generator through a two-channel peristaltic pump, $2 \mathrm{~mL}$ of $2 \% \mathrm{KBH}_{4}$ was added simultaneously to generate mercury vapor, which was carried by a stream of argon gas and trapped in a Pd-Zr-coated graphite tube at $700^{\circ} \mathrm{C}$. Mercury in the graphite tube was then atomized at $1800^{\circ} \mathrm{C}$ under the recommended conditions listed in Table 1.

\section{Results and Discussion}

\section{Effect of the acidity condition}

The efficiency of the generation of mercury vapor in various acidic solutions, including hydrochloric acid, perchloric acid, nitric acid and acetic acid, at different concentrations was investigated (Fig. 1). $\mathrm{HCl}$ was found to have a plateau of integrated absorbance at a concentration range of $0.15-1.5 \mathrm{~mol}$ $\mathrm{L}^{-1}$, which is easier to control than the other acid media, with which small changes around the optimum acidity result in an apparent decrease in the integrated absorbance of mercury. Thus, a $0.2 \mathrm{~mol} \mathrm{~L} \mathrm{~L}^{-1}$ portion of $\mathrm{HCl}$ was chosen for the generation of mercury vapor.

\section{Effect of the potassium tetrahydroborate concentration}

A reduction solution of potassium tetrahydroborate was used to generate mercury vapor. The dependence of the integrated absorbance of mercury in $0.2 \mathrm{~mol} \mathrm{~L}^{-1} \mathrm{HCl}$ on the potassium tetrahydroborate concentration was investigated. Below $1.0 \%(\mathrm{w} / \mathrm{v})$ of $\mathrm{KBH}_{4}$, the integrated absorbance increased rapidly with increasing concentrations of $\mathrm{KBH}_{4}$, and the integrated absorbance remained constant in a $1.0-4.0 \% \mathrm{KBH}_{4}$ solution when $2 \mathrm{~mL}$ of mercury solution containing $4 \mathrm{ng}$ of mercury was introduced. Therefore, a concentration of $2.0 \%(\mathrm{w} / \mathrm{v}) \mathrm{KBH}_{4}$ was used throughout.

\section{Effect of the trapping temperature}

During direct aqueous sample injection in graphite-furnace AAS, it has been reported that the steps taken to ensure that the palladium modifier was reduced to the metallic palladium, as 


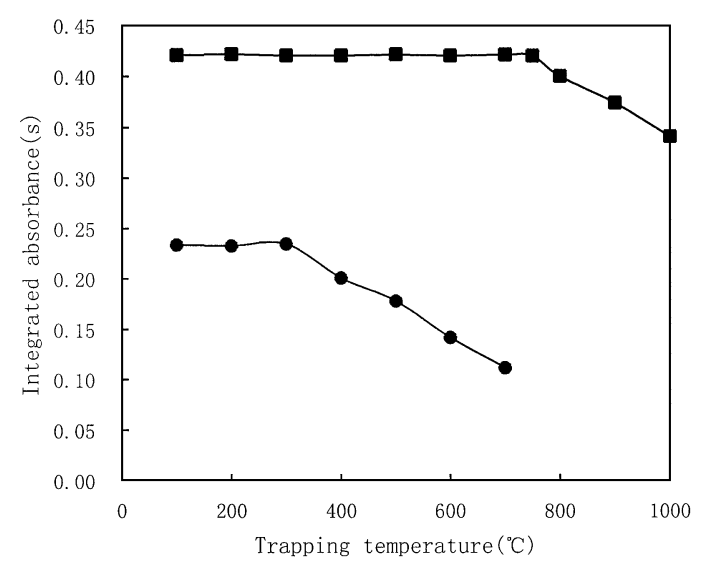

Fig. 2 Effect of the trapping temperature on the integrated absorbance of $4 \mathrm{ng}$ of mercury: ( $\mathbf{a})$ with $\mathrm{Pd}-\mathrm{Zr}$ mixed modifier and (•) with $\mathrm{PdCl}_{2}$ modifier.

early as possible, greatly improved its performance. As reported, ${ }^{19-21}$ preheating the palladium modifier to $1000^{\circ} \mathrm{C}$ or using reduction reagents, such as ascorbic acid and hydrogen, could reduce the palladium to its metallic form. However, on the contrary, Yan et al. ${ }^{16}$ reported that the reduction of $\mathrm{PdCl}_{2}$ to the metal is less favorable for mercury trapping with $\mathrm{PdCl}_{2}$ as a modifier. In order to compare the trapping efficiency, $\mathrm{PdCl}_{2}$ without the addition of ascorbic acid and $\mathrm{Pd}-\mathrm{Zr}$ was used.

The effect of the trapping temperature on the integrated absorbance of mercury was investigated; the results are shown in Fig. 2. A higher integrated absorbance was observed when $\mathrm{Pd}-\mathrm{Zr}$ mixed modifier was used as the mixed trapping agent (modifier) compared with the use of $\mathrm{PdCl}_{2}$. The results indicate that the trapping efficiency is much higher with $\mathrm{Pd}-\mathrm{Zr}$ as the trapping medium and modifier. In addition, the results given in Fig. 2 indicate that the trapping temperature also influences the trapping efficiency of mercury vapor. A temperature of $750^{\circ} \mathrm{C}$ was achieved using $\mathrm{Pd}-\mathrm{Zr}$ as the modifier, while a temperature of $300^{\circ} \mathrm{C}$ was obtained with $\mathrm{PdCl}_{2}$ as the modifier, thus confirming the results of Yan et al. ${ }^{16}$

\section{Effect of the gas-flow rate}

Argon carrier gas was used to strip and transport the mercury vapor into the graphite furnace. According to results reported by Tao and Fang, ${ }^{22}$ the effects from the carrier gas flow rate were negligible and the amount of hydrogen generated during the reaction was sufficient to transport the hydride into the graphite furnace for HGAAS; therefore, no carrier gas was used in their experiment. In our work, however, the integrated absorbance of mercury significantly depended on the gas-flow rate. The mercury vapor was completely stripped from vapor generator and trapped in the furnace at an argon flow rate of 300 $-800 \mathrm{~mL} \mathrm{~min}{ }^{-1}$ with a $30 \mathrm{~s}$ of collection time. The integrated absorbance of mercury decreased with increasing the gas-flow

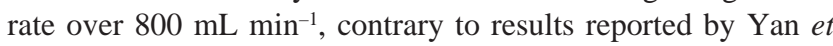
al..$^{16}$ An argon flow of $350 \mathrm{~mL} \mathrm{~min}^{-1}$ was used throughout the experiment in order to transport the mercury vapor completely.

\section{Effect of the collection time}

After the generation of mercury vapor, a period of time is required for stripping the residual vapor out of the solution and sweeping it into the graphite tube. It is obvious that the integrated absorbance of mercury remained almost constant after a $20 \mathrm{~s}$ collection time. In order to ensure that all of the

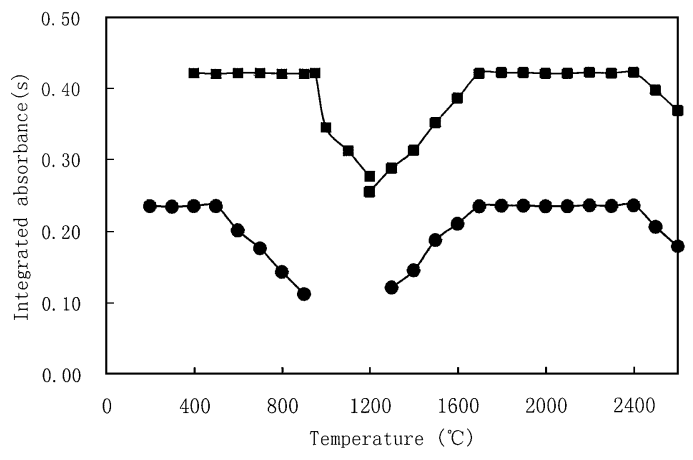

Fig. 3 Pyrolysis and atomization temperatures of 4 ng of mercury: (匹) with $\mathrm{Pd}-\mathrm{Zr}$ mixed modifier and (•) with $\mathrm{PdCl}_{2}$ modifier.

mercury vapor was completely trapped in the graphite tube, a collection time of $30 \mathrm{~s}$ was selected throughout the experiment.

\section{Pyrolysis and atomization temperature}

With $\mathrm{Pd}-\mathrm{Zr}$ as a mixed modifier and trapping medium, the pyrolysis temperature could be improved to $950^{\circ} \mathrm{C}$ (Fig. 3), whereas a pyrolysis temperature of only $500^{\circ} \mathrm{C}$ was obtained with $\mathrm{PdCl}_{2}$ as the modifier. The interferences can be reduced by using a higher pyrolysis temperature in GFAAS. The Pd-Zr mixed solution is more effective for the determination of mercury both as the trapping medium and the matrix modifier. From the results of our interference study, the interferences caused by some metals are found to be more severe when a pyrolysis temperature of $950^{\circ} \mathrm{C}$ is used, but they can be tolerated at a pyrolysis temperature of $600^{\circ} \mathrm{C}$ after the addition of $0.2 \%$ EDTA; thus, pyrolysis temperature of $700^{\circ} \mathrm{C}$ is chosen, which is as the same as the trapping temperature for normal operation.

Plateaus of the atomization temperature were observed over 1700 - $2400^{\circ} \mathrm{C}$ using $\mathrm{PdCl}_{2}$ and $\mathrm{Pd}-\mathrm{Zr}$ modifiers (Fig. 3); therefore, an atomization temperature of $1800^{\circ} \mathrm{C}$ was selected. In addition, the "maximum power" mode is often selected in the analysis of many elements in order to achieve the maximum sensitivity. However, the results in this work show that the highest integrated absorbance was obtained using a ramp time of $1 \mathrm{~s}$, rather than the "maximum power" mode. A ramp atomization program was used instead of "maximum power" heating in order to avoid the loss of mercury due to a rapid diffusion of mercury.

\section{Effect of the concentration of palladium on the trapping efficiency of mercury vapor}

In order to investigate the effect of the mass of palladium on the trapping efficiency of mercury vapor, different amounts of palladium were added to trap mercury vapor in graphite tube. The results show that before $20 \mu \mathrm{g}$ of palladium, the trapping efficiency increased along with an increase in the amount of palladium; the best efficiency was obtained with the addition of $20 \mu \mathrm{g}$ of palladium for $0-34 \mathrm{ng}$ of mercury. Therefore, $25 \mu \mathrm{g}$ of palladium in the form of $\mathrm{PdCl}_{2}$ was added to the graphite tube to trap mercury vapor.

\section{Interference study}

The effects of some foreign ions, such as copper, nickel, iron, selenium, germanium, cobalt, zinc, calcium, arsenic, tellurium, magnesium and manganese, were investigated. The results indicate that no interference was found in the presence of 
Table 2 Analytical results for standard reference materials

\begin{tabular}{lcc}
\hline \multicolumn{1}{c}{ Sample } & $\begin{array}{c}\text { Mercury content } \\
\mu \mathrm{g} \mathrm{g}^{-1}\end{array}$ & $\begin{array}{c}\text { Mercury found } \\
\mu \mathrm{g} \mathrm{g}^{-1}\end{array}$ \\
\hline Mussel (GBW08571) & $0.067 \pm 0.008$ & $0.066 \pm 0.009$ \\
Liver (GBW08306) & $0.052 \pm 0.006$ & $0.050 \pm 0.006$ \\
Peach leaf (GBW08501) & $0.046 \pm 0.012$ & $0.044 \pm 0.010$ \\
Tea leaf (GBW080001) & $0.017 \pm 0.010$ & $0.018 \pm 0.011$ \\
\hline
\end{tabular}

a. Mean value standard deviation $(n=3)$.

$10^{2}-10^{4}$ fold of germanium, arsenic, selenium, zinc, calcium, magnesium and tellurium. The interferences from copper, nickel, cobalt, iron and manganese on the generation of mercury vapor could be eliminated when $0.2 \%$ EDTA was added.

\section{Analytical figure of merit}

The characteristic mass of mercury, which is defined as the mass of the analyte which provides an integrated absorbance of $0.0044 \mathrm{~s}$, was found to be $42 \mathrm{pg}$, and the absolute detection limit $(3 \sigma)$ of mercury based on the variability of the reagent blank was found to be $33 \mathrm{pg}$. The precision of the proposed method was $2.1 \%$ for $4 \mathrm{ng}$ of mercury $(n=7)$. The regression equation for the calibration curve is $y=0.1055 x-0.00003$ with a correlation coefficient of 0.9980 , where $x$ is the analyte mass (ng) and $y$ is the integrated absorbance. The linear range of the regression equation is 0 to $34 \mathrm{ng}$ of mercury.

The efficiency of the collection system was evaluated to $96.2 \%$, which is higher than that obtained with $\mathrm{PdCl}_{2}$ as a modifier, comparing the characteristic mass determined with that determined by direct-injection GFAAS using the same matrix modifier.

\section{Sample analysis}

In order to demonstrate the reliability of the proposed method, it was applied to the analysis of some standard reference materials: Mussel (GBW08571), Bovine liver (GBW08306), Peach leaf (GBW08501) and Tea leaf (GBW080001). The analytical results are summarized in Table 2; the values obtained for mercury compare well with the reference values. In addition, the proposed method was applied to the analysis of some biological tissue samples. In order to examine any systematic errors associated with the determination, the mercury standard solution was spiked for the recovery study; the results are listed in Table 3.

\section{Conclusion}

A mixed chemical matrix modifier was used to trap mercury vapor in the graphite furnace in this work. The characteristic mass and absolute detection limit of mercury using the $\mathrm{Pd}-\mathrm{Zr}$ mixed chemical modifier were improved compared with those obtained using $\mathrm{PdCl}_{2}$ as the modifier and trapping medium. The proposed method was successfully used to analyze trace mercury in biological tissue samples with satisfactory recoveries.

\section{Acknowledgements}

This work was supported by Natural Science Foundation of
Table 3 Analytical and recovery results from real samples

\begin{tabular}{cccc}
\hline Sample & $\begin{array}{c}\text { Mercury content/ } \\
\mu \mathrm{g} \mathrm{g}^{-1}\end{array}$ & $\begin{array}{c}\text { Mercury spiked/ } \\
\mu \mathrm{g} \mathrm{g}^{-1}\end{array}$ & $\begin{array}{c}\text { Recovery } \\
\text { (average), \% }\end{array}$ \\
\hline Rabbit kidney 1 & 1.0254 & $0.5,1.0,1.5$ & 105 \\
Rabbit kidney 2 & 0.821 & $0.5,1.0,1.5$ & 97 \\
Rabbit kidney 3 & 0.748 & $0.5,1.0,1.5$ & 96 \\
Rabbit kidney 4 & 0.915 & $0.5,1.0,1.5$ & 98 \\
Rabbit kidney 5 & 0.737 & $0.5,1.0,1.5$ & 102 \\
Rabbit liver 1 & 0.0455 & $0.05,0.10$ & 94 \\
Rabbit liver 2 & 0.0862 & $0.05,0.10$ & 96 \\
Rabbit liver 3 & 0.0881 & $0.05,0.10$ & 99 \\
Rabbit liver 4 & 0.0923 & $0.05,0.10$ & 95 \\
Rabbit liver 5 & 0.0450 & $0.05,0.10$ & 94 \\
\hline
\end{tabular}

Hebei Province, P. R. China (Contract No. 299076).

\section{References}

1. I. Sanemasa, E. Takagi, T. Deguchi, and H. Nagai, Anal. Chim. Acta, 1991, 130, 149.

2. S. Mandal and A. Das, At. Spectrosc., 1982, 3, 56.

3. G. Topping and J. M. Pirie, Anal. Chim. Acta, 1972, 62, 200.

4. B. Welz, M. Melcher, H. W. Sinemus, and D. Maier, At. Spectrosc., 1984, 5, 37.

5. J. Murphy, At. Absorpt. Newslett., 1975, 14, 151.

6. E. Temmerman, C. Vandecasteele, G. Vermeir, R. Leyman, and R. Dams, Anal. Chim. Acta, 1990, 236, 371.

7. S. McIntosh, At. Spectrosc., 1994, 14, 47.

8. B. Welz and M. Schubert-Jacobs, Fresenius' Z. Anal. Chem., 1998, 331, 324.

9. B. Welz, "Atomic Absorption Spectrometry", 2nd ed., 1985, $\mathrm{VCH}$, Weinheim.

10. D. C. Baxter and W. Frech, Anal. Chim. Acta, 1989, 225 , 175.

11. D. D. Siemer and L. Hageman, Anal. Chem., 1980, 52, 105.

12. S. H. Lee, K. H. Jung, and D. S. Lee, Talanta, 1989, 36, 999.

13. Z. Hladky, J. Risova, and M. Fisera, J. Anal. At. Spectrom., 1990, 5,691 .

14. E. Bulska and W. Jedral, J. Anal. At. Spectrom., 1995, 10, 49.

15. X. Q. Shan and Z. M. Ni, Acta Chim. Sin., 1979, 37, 261.

16. X. P. Yan, Z. M. Ni, and Q. L. Guo, Anal. Chim. Acta, 1993, 272, 105.

17. D. Q. Zhang, L. L. Yang, J. M. Sun, and H. W. Sun, Fresenius' J. Anal. Chem., 1999, 363, 359.

18. Y. Q. Gao and Z. M. Ni, Acta Chim. Sin., 1982, 40, 1021.

19. L. M. Voth-Beach and D. E. Schrader, Spectroscopy, 1986, 1,49

20. T. M. Rettberg and L. M. Beach, J. Anal. At. Spectrom., 1989, $2,45$.

21. A. Volynsky, S. Tikhomirov, and A. Elagin, Analyst, 1991, 116,145

22. G. H. Tao and Z. L. Fang, J. Anal. At. Spectrom., 1993, 8, 577. 